\title{
Analisis Faktor-Faktor yang Berhubungan dengan Kelengkapan Imunisasi Dasar pada Balita di Desa Ujung Bawang Aceh Singkil
}

\author{
Analysis of Related Factors with Complete Basic Immunization Ontoddlers in \\ Ujung Bawang Village Aceh Singkil
}

\author{
Faradilla Safitri*1, Mufdalina ${ }^{2}$, Fauziah Andika ${ }^{3}$ \\ ${ }^{1,2}$ Program Studi D-IV Kebidanan, Fakultas Ilmu Kesehatan, Universitas Ubudiyah Indonesia, Banda Aceh, Indonesia \\ ${ }^{3}$ Program Studi S1 Ilmu Kesehatan Masyarakat, Fakultas Ilmu Kesehatan, Universitas Ubudiyah Indonesia, Banda Aceh, \\ Indonesia
}

*Korespondensi Penulis: $\underline{\text { faradilla@uui.ac.id }}$

\begin{abstract}
Abstrak
Imunisasi merupakan usaha memberikan kekebalan pada anak dengan memasukkan vaksin kedalam tubuh agar tubuh membuat zat anti untuk mencegah penyakit tertentu. Tujuan dari penelitian ini untuk menganalisis faktor-faktor yang berhubungan dengan kelengkapan imunisasi dasar pada balita di Desa Ujung Bawang Aceh Singkil Tahun 2017. Jenis penelitian analitik dengan pendekatan cross-sectional. Populasinya seluruh ibu yang memiliki balita sebanyak 42 orang, pengambilan sampel dengan cara total populasi. Pengumpulan data tanggal 30 Maret s/d 14 April 2017. Hasil analisis bivariat diperoleh pendidikan ( $p$ value $=1.000)$, pengetahuan ( $p$-value $=0.000)$, status pekerjaan $(p$-value $=1.000)$, jumlah anak $(p$-value $=0.173)$, sikap $(p$-value $=0.008)$ dan keterjangkauan tempat pelayanan kesehatan $(p$ value $=0.354)$. Kesimpulan hasil penelitian ini adalah ada hubungan pengetahuan dan sikap dengan kelengkapan imunisasi dasar pada balita sedangkan tidak ada hubungan pendidikan, status pekerjaan, jumlah anak dan keterjangkauan tempat pelayanan kesehatan dengan kelengkapan imunisasi dasar pada balita di Desa Ujung Bawang Aceh Singkil Tahun 2017.
\end{abstract}

Kata kunci : imunisasi dasar, pengetahuan, sikap.

\begin{abstract}
Immunization is an effort to provide immunity to children by entering the vaccine into the body so that the body makes anti-substance to prevent certain diseases. The purpose of this study was to analyze factors related to the completeness of basic immunization in under-five children in Ujung BawangVillage Aceh Singkil in 2017. Type of analytical research was cross-sectional approach. The populationswere all mothers who have toddlers as many as 42 people, sampling of this research was total population. Data collection was collected in 30 March to 14 April 2017. The result of bivariate analysis produces education ( $P$-value = $1,000)$, knowledge ( $p$-value $=0.000)$, employment status $(p$-value $=1,000)$, number of children $(p$-value $=1,000) P$-value $=0.173)$, attitude $(p$-value $=0.008)$ And affordability of health service ( $p$-value $=0.354)$. The conclusion of this research is the correlation between knowledge and attitude with the completeness of basic immunization on toddlers while there are no relation of education, employment status, number of children and affordability of
\end{abstract}


health service facilities with basic immunization completeness in children of Ujung Bawang Aceh Singkil 2017.

Keywords: Basic immunization, knowledge, attitude.

\section{PENDAHULUAN}

Lingkup pelayanan kesehatan bidang preventif merupakan prioritas utama. Dalam melaksanakan Sistem Kesehatan Nasional (SKN), imunisasi merupakan salah satu bentuk intervensi kesehatan yang sangat efektif dalam upaya menurunkan angka kematian bayi dan balita. Penularan insidens penyakit menular telah terjadi berpuluh-puluh tahun yang lampau di negara-negara maju yang telah melakukan imunisasi dengan teratur dengan cakupan luas.

Faktor-faktor yang berhubungan dengan kelengkapan imunisasi dasar meliputi beberapa hal, antara lain adalah pengetahuan, motif, pengalaman, pekerjaan, dukungan keluarga, fasilitas posyandu, lingkungan, sikap, tenaga kesehatan, penghasilan dan pendidikan $^{[12]}$. Data yang diperoleh dari Dinas Kesehatan Provinsi Aceh, diketahui pencapaian cakupan imunisasi di provinsi Aceh tahun 2012 sebesar 60,9\%, tahun 2013 mengalami peningkatan sebesar 71,23\%, tahun 2014 cakupan imunisasi turun kembali menjadi 69,81\%, dan pada tahun 2015 cakupan imunisasi semakin menurun sebesar 67,56\%.

Berdasarkan data dari Dinas Kesehatan Kabupaten Aceh Singkil tahun 2015 cakupan pemberian imunisasi sebesar 87,5\%, Namun di Wilayah Kerja Puskesmas Singkil masih terdapat empat desa yang memiliki cakupan imunisasai tidak memenuhi standar UCI (Universal Coverage Imunization) yaitu cakupan imunisasi lengkap minimal $80 \%$ secara merata yaitu di Desa Teluk Rumbia (76\%), Ujung Bawang (69\%), Suka Damai (73\%) dan Rantau Gedang (75\%). Namun dalam penelitian ini, peneliti akan melakukan penelitian di Desa Ujung Bawang, hal ini dikarenakan Desa Ujung Bawang memiliki angka terendah cakupan imunisasi dan memiliki jumlah populasi yang besar (Puskesmas Singkil 2015).

\section{METODE PENELITIAN}

Penelitian ini menggunakan jenis penelitian yang bersifat survey analitik dengan desain cross-sectional. Populasi dalam penelitian ini adalah seluruh ibu yang memiliki balita yang berada di Desa Ujung Bawang Aceh Singkil Tahun 2017 yaitu sebanyak 42 orang. Pengambilan sampel dalam penelitian ini ada total populasi, yaitu seluruh populasi dijadikan sampel. Instrumen pengumpulan data menggunakan kuesioner dengan cara wawancara. 
Pengumpulan data telah dilaksanakan pada tanggal 30 Maret s/d 14 April 2017 di Desa Ujung Bawang Aceh Singkil.

\section{HASIL DAN PEMBAHASAN}

Tabel 1. Hubungan pendidikan dengan kelengkapan imunisasi dasar pada balita di Desa Ujung Bawang Singkil Tahun 2017

\begin{tabular}{|c|c|c|c|c|c|c|c|c|}
\hline \multirow[t]{3}{*}{ No } & \multirow[t]{3}{*}{ Pendidikan } & \multicolumn{4}{|c|}{$\begin{array}{c}\text { Kelengkapan Imunisasi } \\
\text { Dasar }\end{array}$} & \multirow{2}{*}{\multicolumn{2}{|c|}{ Total }} & \multirow[t]{3}{*}{$\begin{array}{c}P \\
\text { Value }\end{array}$} \\
\hline & & \multicolumn{2}{|c|}{$\begin{array}{c}\text { Tidak } \\
\text { Lengkap }\end{array}$} & \multicolumn{2}{|c|}{ Lengkap } & & & \\
\hline & & $\mathbf{f}$ & $\%$ & $\mathbf{f}$ & $\%$ & $\mathbf{n}$ & $\%$ & \\
\hline 1 & Rendah & 9 & 31,0 & 20 & 69,0 & 29 & 100 & 1.000 \\
\hline 2 & Tinggi & 4 & 30,8 & 9 & 69,2 & 13 & 100 & \\
\hline
\end{tabular}

Berdasarkan Tabel 1, dapat dilihat bahwa dari 13 responden, yang pendidikannya tinggi sebanyak 69,2\% lengkap memberikan imunisasi dasar pada balita, sedangkan dari 29 responden, yang berpendidikan rendah sebanyak 69,0\% lengkap memberikan imunisasi pada balitanya. Hasil uji statistik didapat nilai $\mathrm{p}=1.000$ ( $\mathrm{p}>0.05)$, artinya tidak ada hubungan antara pendidikan ibu dengan kelengkapan imunisasi pada balita di Desa Ujung Bawang Aceh Singkil Tahun 2017.

Tabel 2. Hubungan pengetahuan dengan kelengkapan imunisasi dasar pada balita di Desa Ujung Bawang Singkil Tahun 2017

\begin{tabular}{|c|c|c|c|c|c|c|c|c|}
\hline \multirow[t]{3}{*}{ No } & \multirow[t]{3}{*}{ Pengetahuan } & \multicolumn{4}{|c|}{ Kelengkapan Imunisasi Dasar } & \multirow{2}{*}{\multicolumn{2}{|c|}{ Total }} & \multirow[t]{3}{*}{ P Value } \\
\hline & & \multicolumn{2}{|c|}{$\begin{array}{c}\text { Tidak } \\
\text { Lengkap }\end{array}$} & \multicolumn{2}{|c|}{ Lengkap } & & & \\
\hline & & $\mathbf{f}$ & $\%$ & $\mathbf{f}$ & $\%$ & $\mathbf{n}$ & $\%$ & \\
\hline 1 & Rendah & 12 & 100,0 & 0 & 0,0 & 12 & 100 & 0.000 \\
\hline 2 & Tinggi & 1 & 3,3 & 29 & 96,7 & 30 & 100 & \\
\hline
\end{tabular}

Berdasarkan Tabel 2, dapat dilihat bahwa dari 12 responden, yang pengetahuannya rendah sebanyak 100,0\% tidak lengkap memberikan imunisasi dasar pada balita, sedangkan dari 30 responden, yang berpengetahuan tinggi sebanyak 3,3\% tidak lengkap memberikan imunisasi pada balitanya. Hasil uji statistik didapat nilai $\mathrm{p}=0.000(\mathrm{p}<0.05)$, artinya ada hubungan antara pengetahuan ibu dengan kelengkapan imunisasi pada balita di Desa Ujung Bawang Aceh Singkil Tahun 2017. 
Tabel 3. Hubungan status pekerjaan dengan kelengkapan imunisasi dasar pada balita di Desa Ujung Bawang Singkil Tahun 2017

\begin{tabular}{llccccccc}
\hline No & $\begin{array}{c}\text { Status } \\
\text { Pekerjaan }\end{array}$ & \multicolumn{2}{c}{ Kelengkapan Imunisasi Dasar } & & Total & \multirow{2}{*}{\begin{tabular}{c} 
P Value \\
\cline { 3 - 7 }
\end{tabular}} & $\begin{array}{c}\text { Tidak } \\
\text { Lengkap }\end{array}$ & \multicolumn{2}{c}{ Lengkap } & & & \\
\cline { 3 - 8 } & f & \% & f & \% & n & \% & \\
\hline 1 & Tidak Bekerja & 12 & 31,6 & 26 & 68,4 & 38 & 100 & 1.000 \\
2 & Bekerja & 1 & 25,0 & 3 & 75,0 & 4 & 100 & \\
\hline
\end{tabular}

Berdasarkan Tabel 3, dapat dilihat bahwa dari 4 responden, yang bekerja sebanyak 75,0\% lengkap memberikan imunisasi dasar pada balita, sedangkan dari 38 responden, yang tidak bekerja sebanyak 68,4\% lengkap memberikan imunisasi pada balitanya. Hasil uji statistik didapat nilai $\mathrm{p}=1.000(\mathrm{p}>0.05)$, artinya tidak ada hubungan antara status pekerjaan ibu dengan kelengkapan imunisasi pada balita di Desa Ujung Bawang Aceh Singkil Tahun 2017.

Tabel 4. Hubungan jumlah anak dengan kelengkapan imunisasi dasar pada balita di Desa Ujung Bawang Singkil Tahun 2017

\begin{tabular}{|c|c|c|c|c|c|c|c|c|}
\hline \multirow[t]{3}{*}{ No } & \multirow[t]{3}{*}{ Jumlah Anak } & \multicolumn{4}{|c|}{ Kelengkapan Imunisasi Dasar } & \multirow{2}{*}{\multicolumn{2}{|c|}{ Total }} & \multirow[t]{3}{*}{ P Value } \\
\hline & & \multicolumn{2}{|c|}{$\begin{array}{c}\text { Tidak } \\
\text { Lengkap }\end{array}$} & \multicolumn{2}{|c|}{ Lengkap } & & & \\
\hline & & $\mathbf{f}$ & $\%$ & $\mathbf{f}$ & $\%$ & $\mathbf{n}$ & $\%$ & \\
\hline 1 & $\geq 3$ anak & 6 & 46,2 & 7 & 53,8 & 17 & 100 & 0.173 \\
\hline 2 & $<3$ anak & 7 & 24,1 & 22 & 75,9 & 29 & 100 & \\
\hline
\end{tabular}

Berdasarkan Tabel 4, dapat dilihat bahwa dari 29 responden, yang memilki anak $<3$ sebanyak 75,9\% lengkap memberikan imunisasi dasar pada balita, sedangkan dari 17 responden, yang memiliki anak $\geq 3$ sebanyak 53,8\% lengkap memberikan imunisasi pada balitanya. Hasil uji statistik didapat nilai $\mathrm{p}=0.173$ ( $\mathrm{p}>0.05)$, artinya tidak ada hubungan antara jumlah anak dengan kelengkapan imunisasi pada balita di Desa Ujung Bawang Aceh Singkil Tahun 2017. 
Tabel 5. Hubungan sikap dengan kelengkapan imunisasi dasar pada balita di Desa Ujung Bawang Singkil Tahun 2017

\begin{tabular}{|c|c|c|c|c|c|c|c|c|}
\hline \multirow[t]{3}{*}{ No } & \multirow[t]{3}{*}{ Sikap } & \multicolumn{4}{|c|}{ Kelengkapan Imunisasi Dasar } & \multirow{2}{*}{\multicolumn{2}{|c|}{ Total }} & \multirow[t]{3}{*}{$P$ Value } \\
\hline & & \multicolumn{2}{|c|}{$\begin{array}{c}\text { Tidak } \\
\text { Lengkap } \\
\end{array}$} & \multicolumn{2}{|c|}{ Lengkap } & & & \\
\hline & & $\mathbf{f}$ & $\%$ & $\mathbf{f}$ & $\%$ & $\mathbf{n}$ & $\%$ & \\
\hline 1 & Negatif & 10 & 55,6 & 8 & 44,4 & 18 & 100 & 0.008 \\
\hline 2 & Positif & 3 & 12,5 & 21 & 87,5 & 24 & 100 & \\
\hline
\end{tabular}

Berdasarkan Tabel 5, dapat dilihat bahwa dari 24 responden, yang bersikap positif sebanyak 87,5\% lengkap memberikan imunisasi dasar pada balita, sedangkan dari 18 responden, yang bersikap negatif sebanyak 44,4\% lengkap memberikan imunisasi pada balitanya. Hasil uji statistik didapat nilai $\mathrm{p}=0.008(\mathrm{p}<0.05)$, artinya ada hubungan sikap dengan kelengkapan imunisasi pada balita di Desa Ujung Bawang Aceh Singkil Tahun 2017.

Tabel 6. Hubungan Keterjangkauan Tempat Pelayanan Kesehatan Dengan Kelengkapan imunisasi dasar pada balita di Desa Ujung Bawang Singkil Tahun 2017

\begin{tabular}{|c|c|c|c|c|c|c|c|c|}
\hline \multirow[t]{3}{*}{ No } & \multirow{3}{*}{$\begin{array}{c}\text { Keterjangkauan } \\
\text { tempat pelayanan } \\
\text { kesehatan }\end{array}$} & \multicolumn{4}{|c|}{ Kelengkapan Imunisasi Dasar } & \multirow{2}{*}{\multicolumn{2}{|c|}{ Total }} & \multirow{3}{*}{ P Value } \\
\hline & & \multicolumn{2}{|c|}{$\begin{array}{c}\text { Tidak } \\
\text { Lengkap }\end{array}$} & \multicolumn{2}{|c|}{ Lengkap } & & & \\
\hline & & $\mathbf{f}$ & $\%$ & $\mathbf{f}$ & $\%$ & $\mathbf{n}$ & $\%$ & \\
\hline 1 & Jauh & 4 & 21,1 & 15 & 78,9 & 19 & 100 & 0.354 \\
\hline 2 & Dekat & 9 & 39,1 & 14 & 60,9 & 23 & 100 & \\
\hline
\end{tabular}

Berdasarkan Tabel 6, dapat dilihat bahwa dari 19 responden, yang jarak ke tempat pelayanan kesehatan jauh sebanyak 78,9\% lengkap memberikan imunisasi dasar pada balita, sedangkan dari 23 responden, yang jarak ke tempat pelayanan kesehatan dekat sebanyak $60,9 \%$ lengkap memberikan imunisasi pada balitanya. Hasil uji statistik didapat nilai $\mathrm{p}=$ 0.354 ( $\mathrm{p}>0.05$ ), artinya tidak ada hubungan keterjangkauan tempat pelayanan kesehatan dengan kelengkapan imunisasi pada balita di Desa Ujung Bawang Aceh Singkil Tahun 2017.

\section{Pembahasan}

1. Analisis Hubungan Pendidikan dengan Kelengkapan Imunisasi Dasar pada Balita

Hasil penelitian menunjukkan bahwa ibu yang berpendidikan tinggi $69.2 \%$ memberikan imunisasi dasar lengkap pada anaknya, hal ini tidak jauh berbeda dengan ibu 
yang berpendidikan rendah $69.0 \%$ juga memberikan imunisasi dasar lengkap pada anaknya. Hasil uji statistik diperoleh bahwa tidak ada hubungan pendidikan ibu dengan kelengkapan imunisasi pada balita dengan nilai $\mathrm{p}=1.000(\mathrm{p}>0.05)$.

Hasil penelitian ini sejalan dengan penelitian yang dilakukan oleh Rahmadhani di Desa Balegondo Kecamatan Ngariboyo Kabupaten Magetan dengan hasil bahwa tidak ada hubungan pendidikan ibu dengan kelengkapan imunisasi dasar pada balita dengan nilai $\mathrm{p}=$ $0.098^{[11]}$. Sama halnya dengan hasil penelitian yang dilakukan oleh Albertina, tidak terdapat hubungan pendidikan ibu dengan kelengkapan imunisasi dasar anak balita di Poliklinik Anak beberapa Rumah Sakit di Jakarta (Albertina, dkk, 2008). Hasil penelitian Azizah, Mifbakhuddin dan Mulyanti di Desa Sumberejo Kecamatan Mranggen Demak dengan hasil tidak ada hubungan faktor pendidikan ibu dengan kelengkapan imunisasi pada anak, dengan nilai $\mathrm{p}=0.714$ (Azizah, Mifbakhuddin dan Mulyanti, 2012). Hasil penelitian Ismet di Desa Botunarani Kecamatan Kabila Bone Bolango, ditemukan nilai $\mathrm{p}=0.214$, yang artinya tidak ada hubungan pendidikan ibu dengan imunisasi dasar lengkap pada balita (Ismet, F. 2014).

Pendidikan adalah salah satu usaha sadar untuk mengembangkan kepribadian dan kemampuan di dalam dan luar sekolah dan berlangsung seumur hidup. Pendidikan menentukan pola pikir dan wawasan seseorang. Pendidikan memiliki peranan yang penting dalam kwalitas. Lewat pendidikan manusia dianggap akan memperoleh pengetahuan (Notoatmodjo, S. 2003).

Teori yang disampaikan berbeda dengan hasil penelitian yang telah dilakukan peneliti, hal ini bisa disebabkan karena seseorang yang berpendidikan rendah bisa mendapatkan pengetahuan khususnya tentang imunisasi oleh para petugas kesehatan, iklan di televisi, media massa atau media sosial, dll. Sama halnya dengan ibu yang memiliki balita di Desa Ujung Bawang rata-rata berpendidikan rendah, namun tidak semua mempengaruhi pemberian imunisasi dasar pada anaknya. Ada pula 13 orang ibu yang memiliki balita yang tidak memberikan imunisasi pada anaknya, hal ini bisa disebabkan karena berbagai isu tentang vaksin yang negatif, sehingga mereka enggan untuk memberikan imunisasi pada anaknya. Dengan demikian, pendidikan formal tidak menjadi faktor utama yang dapat mendukung seseorang dalam penyerapan informasi dan perubahan perilaku kepada hal yang positif, namun perilaku seseorang dapat dipengaruhi oleh banyak faktor lainnya. 
2. Analisis Hubungan Pengetahuan dengan Kelengkapan Imunisasi Dasar pada Balita

Hasil penelitian menujukkan bahwa ibu yang berpengetahuan rendah $100.0 \%$ tidak memberikan imunisasi dasar lengkap pada anaknya dengan nilai $\mathrm{p}=0.000$, yang berarti ada hubungan pengetahuan ibu tentang imunisasi dengan kelengkapan imunisasi dasar pada balita di Desa Ujung Bawang tahun 2017.

Hasil penelitian ini sejalan dengan penelitian yang dilakukan oleh Kadir, Fatimah dan Hadla di Puskesmas Buntu Batu Kecamatan Buntu Batu Kabupaten Enrekang dengan nilai $\mathrm{p}=0.001$, yang berarti ada hubungan yang signifikan antara pengetahuan ibu dengan pemberian imunisasi dasar pada bayi (Kadir, Fatimah dan Hadla, 2014). Hasil penelitian yang dilakukan oleh Triana di Kecamatan Kuranji Kota Padang bahwa ada hubungan pengetahuan dengan pemberian imunisasi dasar lengkap pada bayi dengan nilai $\mathrm{p}=0.007$ (Triana, Vivi. 2015).

Pengetahuan merupakan hasil dari tahu yang terjadi setelah seseorang melakukan penginderaan terhadap objek tertentu. Sebagian besar pengetahuan diperoleh melalui indera penglihatan dan pendengaran. Pengetahuan diperlukan dalam menimbulkan rasa percaya diri maupun sikap dan perilaku setiap hari, sehingga dapat dikatakan bahwa pengetahuan merupakan domain yang sangat penting terhadap pembentukan tindakan seseorang. Pengetahuan tentang penyakit dapat mempengaruhi persepsi seseorang terhadap suatu penyakit yang pada akhirnya dapat mempengaruhi perilaku seseorang untuk mengurangi ancaman dari suatu penyakit (Azwar, S. 2005).

Peneliti berasumsi bahwa pengetahuan menjadi dasar sebuah tindakan agar ibu membawa bayinya ketempat pelayanan kesehatan untuk memberikan imunisasi pada anaknya, ibu yang memiliki pengetahuan yang baik tentang imunisasi maka akan termotivasi untuk memberikan imunisasi pada anaknya, hal ini dikarenakan ibu tersebut telah mengetahui apa manfaat yang akan didapat setelah imunisasi dan kerugian yang didapat jika anak tidak diberi imunisasi. Di Desa Ujung Bawang masih ada 1 orang ibu yang pengetahuannya tinggi namun tidak mau memberikan imunisasi pada anaknya, hal ini dikarenakan tidak mendapatkan dukungan dari suami dan keluarganya yang beranggapan bahwa imunisasi itu program dari orang yahudi. Dengan demikian, petugas kesehatan harus lebih gencar lagi memberikan penyuluhan kesehatan bukan hanya pada ibu namun juga pada seluruh warga yang ada disekitar tentang manfaat imunisasi. 
3. Analisis Hubungan Status Pekerjaan dengan Kelengkapan Imunisasi Dasar pada Balita

Hasil penelitian menunjukkan bahwa dari 4 responden, yang bekerja sebanyak 75,0\% lengkap memberikan imunisasi dasar pada balita, sedangkan dari 38 responden, yang tidak bekerja sebanyak 68,4\% lengkap memberikan imunisasi pada balitanya dengan nilai $\mathrm{p}=1.000(\mathrm{p}>0.05)$, artinya tidak ada hubungan status pekerjaan dengan kelengkapan imunisasi dasar pada balita di Desa Ujung Bawang Aceh Singkil Tahun 2017.

Hasil penelitian ini sejalan dengan hasil penelitian yang dilakukan oleh Paridawati, Rachman dan Fajarwati, tidak ada hubungan pekerjaan ibu dalam pemberian imunisasi dasar pada bayi di Wilayah Kerja Puskesmas Bajeng Kecamatan Bajeng Kabupaten Gowa dengan nilai $\mathrm{p}=0.385$ (Paridawati, Rachman dan Fajarwati, 2013). Hasil penelitian Ismet di Desa Botunarani Kecamatan Kabila Bone Bolango, ditemukan nilai $\mathrm{p}=0.228$, yang artinya tidak ada hubungan antara pekerjaan ibu dengan imunisasi dasar lengkap pada balita (Ismet, F. 2014).

Pekerjaan adalah simbol status seseorang di masyarakat merupakan suatu cara untuk memperoleh uang dalam rangka memenuhi kebutuhan hidup untuk mendapatkan tempat pelayanan kesehatan yang diinginkan (Suparyant, 2014).

Peneliti berasumsi bahwa pekerjaan seorang ibu tidak berdampak terhadap sikap dan tindakan ibu dalam pemberian imunisasi pada anak, karena ibu yang tidak bekerja dapat mendapatkan informasi mengenai imunisasi dari teman sejawat, petugas kesehatan, media massa dan lain sebagainya, sehingga ibu termotivasi untuk memberikan anaknya imunisasi secara lengkap. Begitu pula sebaliknya, ibu yang bekerja juga tidak menuntut kemungkinan untuk tidak memberikan imunisasi anaknya, hal ini dapat disebabkan karena ada beberapa informasi yang negative mengenai vaksin imunisasi.

\section{Analisis Hubungan Jumlah Anak dengan Kelengkapan Imunisasi Dasar pada Balita}

Hasil penelitian menunjukkan bahwa ibu yang memilki anak < 3 sebanyak 75,9\% lengkap memberikan imunisasi dasar pada balita, dengan nilai $\mathrm{p}=0.173(\mathrm{p}>0.05)$, artinya tidak ada hubungan antara jumlah anak dengan kelengkapan imunisasi pada balita di Desa Ujung Bawang Aceh Singkil Tahun 2017.

Hasil penelitian ini sejalan dengan penelitian yang dilakukan oleh Istriyanti, tidak ada hubungan jumlah anak dalam keluarga dengan kelengkapan imunisasi dasar pada bayi 
di Desa Kumpulrejo Kecamatan Argomulyo Kota Salatiga dengan nilai $\mathrm{p}=0.108$ (Istriyati, E. 2011).

Peneliti berasumsi bahwa ibu yang memiliki banyak anak maka akan semakin berpengalaman tentang cara perawatan dan menjaga kesehatan anaknya, contohnya dalam pemberian imunisasi sehingga anak terhindar dari beberapa penyakit berbahaya, sehingga diterapkanlah pemberian imunisasi kepada anak-anak yang lainnya. Namun ada pula ibu yang belum memiliki banyak anak, sehingga belum paham benar tentang imunisasi sehingga tidak memberikan imunisasi pada anaknya.

\section{Analisis Hubungan Sikap dengan Kelengkapan Imunisasi Dasar pada Balita}

Hasil penelitian menunjukkan bahwa ibu yang bersikap positif sebanyak 87,5\% lengkap memberikan imunisasi dasar pada balita dengan nilai $\mathrm{p}=0.008(\mathrm{p}<0.05)$, artinya ada hubungan sikap dengan kelengkapan imunisasi pada balita di Desa Ujung Bawang Aceh Singkil Tahun 2017.

Hasil penelitian ini sejalan dengan hasil penelitian yang dilakukan oleh Azizah, Mifbakhuddin dan Mulyanti di Desa Sumberejo Kecamatan Mranggen Demak dengan hasil ada hubungan faktor sikap ibu dengan kelengkapan imunisasi pada anak, dengan nilai $\mathrm{p}=0.000$ (Azizah, Mifbakhuddin dan Mulyanti, 2012).

Setiap orang yang mempunyai perasaan positif terhadap suatu objek psikologis dikatakan mempunyai sikap favorable terhadap objek itu, sedangkan individu yang mempunyai perasaan negative terhadap suatu objek psikologis dikatakan mempunyai sikap yang unfavorable terhadap objek sikap tersebut (Azwar, S. 2005).

Peneliti berasumsi seorang ibu bisa memiliki sikap positif terhadap pemberian imunisasi hal ini bisa didukung oleh pengetahuan ibu yang sangat baik mengenai imunisasi, peran petugas kesehatan dan lingkungan yang baik, sehingga sikap inilah yang mendorong ibu untuk membawa anaknya ke petugas kesehatan agar diberikan imunisasi, serta ibupun mengingat kapan saja jadwal pemberian imunisasi pada anaknya. Sikap ibu yang positif sangat penting perannya dalam pengambilan keputusan, hal ini dilakukan demi kesehatan anak dan terhindar dari penyakit berbahaya yang bisa dicegah. 
6. Analisis Hubungan Keterjangkauan Tempat Pelayanan Kesehatan dengan Kelengkapan Imunisasi Dasar pada Balita

Hasil penelitian ini menunjukkan bahwa yang jarak ke tempat pelayanan kesehatan jauh sebanyak 78,9\% lengkap memberikan imunisasi dasar pada balita, dengan nilai $\mathrm{p}=$ 0.354 ( $\mathrm{p}>0.05$ ), artinya tidak ada hubungan keterjangkauan tempat pelayanan kesehatan dengan kelengkapan imunisasi pada balita di Desa Ujung Bawang Aceh Singkil Tahun 2017.

Hasil penelitian ini sejalan dengan penelitian yang dilakukan oleh Istriyanti, tidak ada hubungan jarak ke tempat pelayanan imunisasi dengan kelengkapan imunisasi dasar pada bayi di Desa Kumpulrejo Kecamatan Argomulyo Kota Salatiga dengan nilai $p=0.573$ (Istriyati, E. 2011).

Tempat pelayanan yang jaraknya jauh bisa membuat orang enggan mendatanginya. Jauhnya tempat pelayanan kesehatan bisa menyebabkan bertambahnya pengeluaran seperti biaya transportasi. Dengan demikian, sebagian orang memutuskan untuk tidak datang ke tempat pelayanan kesehatan karena tidak terjangkaunya sarana pelayanan kesehatan tersebut (Machfoed dan Sunaryani. 2006).

Peneliti berasumsi bahwa jarak tempat layanan kesehatan tidak menjadi sebuah halangan bagi seorang ibu untuk dapat memberikan imunisasi bagi anaknya, hal ini bisa didasari oleh pengetahuan ibu yang tinggi serta sikap ibu yang positif terhadap imunisasi, dengan demikian ibu tidak akan menghiraukan seberapa jauh perjalanan yang harus ditempuh untuk menuju ke tempat pelayanan kesehatan, hal ini dilakukan demi menjaga kesehatan sang buah hati agar terhindar dari penyakit berbahaya.

\section{KESIMPULAN}

Berdasarkan hasil penelitian dapat disimpulkan bahwa ada hubungan pengetahuan $(p$ value $=0.000)$ dan sikap ibu ( $p$ value $=0.008)$ dengan kelengkapan imunisasi dasar pada balita di Desa Ujung Bawang Aceh Singkil Tahun 2017, sedangkan tidak ada hubungan pendidikan $(p$ value $=1.000)$, status pekerjaan $(p$ value $=1.000)$, jumlah anak $(p$ value $=0.173)$ dan keterjangkauan tempat pelayanan kesehatan $(p$ value $=0.354)$ dengan kelengkapan imunisasi dasar pada balita di Desa Ujung Bawang Aceh Singkil Tahun 2017. 


\section{SARAN}

Diharapkan agar petugas kesehatan baik dari Puskesmas Singkil maupun Dinas Kesehatan Kabupaten Singkil dapat lebih gencar lagi dalam memberikan pelayanan kesehatan dalam bentuk penyuluhan kesehatan yang dapat dilakukan secara rutin dan dapat pula disertai dengan pembagian brosur, pemasangan spanduk atau baliho khususnya tentang pentingnya pemberian imunisasi pada anak, dengan harapan seluruh lapisan masyarakat mendapatkan informasi secara merata tentang imunisasi tersebut, sehingga tidak ada lagi desa yang termasuk kedalam desa yang tidak tercapai cakupan pemberian imunisasi sesuai standar UCI yaitu $80.0 \%$.

\section{UCAPAN TERIMA KASIH}

Ucapan terima kasih kepada Universitas Ubudiyah Indonesia yang telah memberikan dukungan finansial dalam penelitian ini dan ucapan terima kasih kepada Kepala Desa Ujung Bawang Kabupaten Aceh Singkil yang telah memberikan izin penelitian dan para responden yang telah membantu peneliti dalam memberikan informasi yang dibutuhkan peneliti.

\section{DAFTAR PUSTAKA}

Albertina, dkk (2008) Kelengkapan Imunisasi Dasar Anak Balita dan Faktor-faktor yang Berhubungan di Poliklinik Anak beberapa Rumah Sakit di Jakarta. Sari pediatri saripediatri.org.

Azwar, S (2005). Sikap Manusia (Teori dan Pengukurannya). Yogyakarta ; Pustaka Belajar

Azwar, S (2013). Sikap Manusia. Yogyakarta ; Pustaka Belajar.

Azizah, Mifbakhuddin dan Mulyanti (2012) di faktor-faktor yang berhubungan dengan kelengkapan imunisasi dasar pada bayi usia. 9 - 11 bulan di Desa Sumberejo Kecamatan Mranggen Demak. http://jurnal.unimus.ac.id/index.php/jur_bid/article/view/1385 Vol 4, No $1(2015)$

Ranuh, I.G.N, dkk (2008), Pedoman Imunisasi di Indonesia, Jakarta : Ikatan Dokter Anak Indonesia.

Istriyati, E (2011). Faktor-faktor yang Berhubungan dengan Kelengkapan Imunisasi Dasar pada Bayi di Desa Kumpulrejo Kecamatan Argomulyo Kota Salatiga. http://lib.unnes.ac.id.570/1/7055/.

Ismet, F (2014). Analisis faktor-faktor yang Berhubungan dengan Imunisasi Dasar Lengkap pada Balita di Desa Botunarani Kecamatan Kabila Bone Bolango. eprints.ung.ac.i 
Kadir. Fatimah dan Hadla (2014) Pengetahuan dan Kepatuhan Ibu pada Pemberian Imunisasi Dasar Bagi Bayi. Journal of Pediatric Nursing Vol. 1 (1), pp. 009-013, January, 2014. ISSN 2354-726X

Machfoed dan Sunaryani (2006). Pendidikan Kesehatan Bagian dari Promosi Kesehatan. Yogyakarta : Fitramaya.

Notoatmodjo, S (2003). Pendidikan dan Perilaku Kesehatan. Jakarta : PT.Rineka Cipta.

Paridawati, Rachman dan Fajarwati (2013). Faktor yang berhubungan dengan tindakan ibu dalam pemberian imunisasi dasar pada bayi di Wilayah Kerja Puskesmas Bajeng Kecamatan Bajeng Kabupaten Gowa. Jurnal PKIP FKM Universitas . repository.unhas.ac.id.

Rahmadhani (2013). Faktor-Faktor Yang Berhubungan Dengan Kelengkapan Imunisasi Dasar Balita Di Desa Balegondo Kecamatan Ngariboyo Kabupaten Magetan. Skripsi thesis, Universitas Muhammadiyah Surakarta. http://eprints.ums.ac.id/27254

Suparyanto (2014). Konsep Pengetahuan dan Sikap. Diunduh dari : http//dr.Suparyanto.com.

Triana, Vivi (2015). Faktor Yang Berhubungan Dengan Pemberian Imunisasi Dasar Lengkap Kecamatan Kuranji Kota Padang. p-ISSN 1978-3833, e-ISSN 2442-6725. jurnal.fkm.unand.ac.id/index.php/jkma/article/download/ 